\title{
Desinfecção de moldes
}

\author{
Márcia Caroline Marins Santos ${ }^{1}$ \\ Glauber Vieira Duarte ${ }^{I}$ \\ Livia Carvalho ${ }^{2}$ \\ Andrea Pereira Mota ${ }^{2}$ \\ José Flávio Wanderley-Cruz $z^{3}$
}

\begin{abstract}
Resumo
Devido à necessidade de prevenção da contaminação cruzada entre a equipe odontológica e pacientes, inúmeras técnicas e substâncias têm sido utilizadas na promoção da biossegurança em odontologia. Os moldes são classificados como meios de transmissão de microorganismos e, portanto, requerem atenção especial na sua manipulação. O processo de desinfecção de moldes é controverso, e não existe uma padronização universal, variando desde as substâncias utilizadas, suas concentrações, o tempo de desinfecção e até a técnica. Além disso, existe associação entre desinfecção e possibilidade de alteração dimensional dos moldes, propiciando modelos infiéis à condição bucal. O objetivo deste artigo é apresentar técnicas viáveis de desinfecção de moldes, como também alertar os profissionais quanto ao risco da infecção cruzada.
\end{abstract}

Palavras-chave: desinfecção; moldes; modelos.

\section{INTRODUÇÃO}

A explosão de doenças como a AIDS e os grandes riscos relacionados à transmissão do vírus da hepatite $\mathrm{B}$ motivaram pesquisadores a descobrir e divulgar métodos de desinfecção e esterilização utilizados no consultório odontológico, principalmente dos equipamentos e instrumentos que entram em contato com os fluidos corpóreos. Em se tratando de procedimentos protéticos, a infecção cruzada envolve paciente, dentista, atendente e o técnico laboratorial.
Em prótese, as substâncias mais usadas na desinfecção de moldes são o gluteraldeído a $2 \%$ e o hipoclorito de sódio a $1 \%$. Existem outras alternativas, menos utilizadas, como a clorexidina a $0,5 \%$, o iodofórmio, o formaldeído, a radiação ultravioleta e fenóis (PETERSON, 2000).

O glutaraldeído apresenta-se como uma substância esterelizante quando usada em intervalos de tempo prolongados de 10 horas. $\mathrm{Na}$ desinfecção de moldes e modelos com a substância supracitada, preconiza-se um tempo de

\footnotetext{
${ }^{1}$ Acadêmico de Odontologia da Universidade Federal da Bahia. Salvador - BA

2 Professora Substituta de Prótese Fixa I da Faculdade de Odontologia da UFBA. Salvador - BA

${ }^{3}$ Professor Adjunto de Prótese Fixa I do Departamento de Odontologia Clínica da Faculdade de Odontologia da UFBA. Salvador - BA

Correspondência para / Correspondence to:

José Flávio Wanderley-Cruz

Departamento de Odontologia Clínica. Faculdade de Odontologia - UFBA

Rua Araújo Pinho, 62, 5.andar - Canela.

40.000-000 Salvador - Bahia - Brasil.

Tel. (071) 3336-5776.

E-mail: jflavio.cruz@bol.com.br
} 
10 a 30 minutos, sendo esse mesmo tempo aplicado quando do uso do hipoclorito de sódio a $1 \%$, obtendo-se, assim, uma ação antimicrobiana satisfatória (BRASIL, 2000).

A razão para o uso de um tempo reduzido é que, submetendo-se os moldes a essas substâncias por mais de 30 minutos, poder-se-ia provocar alteraçôes dimensionais clinicamente inaceitáveis (INFECTION..., 1996; PAVARINA, 1998).

Os métodos mais utilizados para a desinfecção de moldes com essas substâncias são a imersão e a aspersão. Atualmente, é possível encontrar, no mercado, marcas comerciais de hidrocolóide irreversível (alginato), que apresentam agentes antimicrobianos na sua composição, assim como antibiótico (BASTOS; SOUSA, 2003).

Nos métodos de desinfecção citados, existem vantagens e desvantagens. A imersão, por exemplo, atinge uma maior superfície de contato que o método da aspersão. Entretanto, esse segundo método apresenta menores índices de alteração dimensional (REUGGEBERG, F.A. et al., 1992).

Este trabalho objetiva alertar os profissionais quanto à contaminação cruzada e apresentar técnicas de desinfecção viáveis, de acordo com a literatura atual existente.

\section{REVISÃO DA LITERATURA}

Precaução universal é a filosofia que considera todos os pacientes como infectados com microorganismos patogênicos (PALENIK; BURKE; MILLER, 2000). AIDS, hepatite (A, B, C, Delta, D e E), herpes, tuberculose e doenças infecto-contagiosas relacionadas à profissão do cirurgião-dentista têm chamado a atenção e estimulado cuidados na manipulação de produtos e instrumentais que entram em contato com fluidos corpóreos, como moldes, modelos e trabalhos protéticos (AUTIO et al., 1980). A desinfecção de ambiente e equipamentos, a esterilização de instrumentais, o uso de equipamentos de proteção individual EPI (gorro, luva, máscara, óculos de proteção e aventais) e cuidados especiais com a higienização pessoal são procedimentos realizados com a finalidade de eliminar, ou pelo menos reduzir, a possibilidade de uma infecção direta e (ou) cruzada (ROWE; FORREST, 1978; KUGEL et al., 2000), que pode ser provocada por Streptococcus pyogenes, Staphilococcus aureus, treponema pallidum, Streptococcus pneumoniae, Hemophylus sp, Mycobacterium tuberculosis, Pseudomonas aeruginosa, Neisseria gonorrhoeae, vírus da hepatite e vírus da AIDS (MATHIAS, S.; MATHIAS, A.; GUANDALINE, 1999; PALENIK; BURKE; MILLER, 2000).

Desinfecção é o processo que elimina microorganismos na forma vegetativa, excetuando-se os esporos bacterianos. Esse processo só deve ser indicado na impossibilidade de submeter o material ao processo de esterilização (BRASIL, 2000).

A superfície e o interior de moldes podem conter microorganismos que sobrevivem por longos períodos de tempo longe de seus habitats naturais. Por ser um material hidrófilo, o alginato apresenta a propriedade de embebição, que pode fazer com que, juntamente com os fluidos absorvidos, os microorganismos penetrem com maior facilidade no interior do molde, possibilitando a contaminação dos profissionais que manipulam esse material (OSÓRIO et al., 1998). As substâncias que apresentam resultados satisfatórios e podem ser utilizadas na desinfecção dos moldes são: glutaraldeído a $2 \%$, o hipoclorito de sódio a $1 \%$, digluconato de clorexidina a $0.5 \%$, formaldeído e iodofórmio (PETERSON et al., 2000).

Como método de esterilização de moldes de alginato e siliconas também pode ser utilizada a radiação ultravioleta, que apresenta poder fungicida apenas sobre as áreas em que incide a luz, embora promova a manutenção da integridade dimensional do molde (GARCIA et al., 1995).

O glutaraldeído é o esterilizante químico de escolha para materiais de borracha, plástico e metal, que não podem ser submetidos à este- 
rilização por meios físicos. É uma substância bactericida, tuberculocida, fungicida, viricida e esporicida, tem baixa corrosividade, tendo ação esterilizante por imersão durante dez horas e ação desinfetante por imersão durante dez a trinta minutos. Apresenta toxicidade cutânea e inalatória, tem ação por alquilação e alteração da síntese de proteínas e ácidos nucléicos (WANNMACHER; FERREIRA, 1995).

Entre os desinfetantes existentes com ação sobre os vírus da AIDS e Hepatite, o glutaraldeído e o hipoclorito de sódio são os mais viáveis para o uso rotineiro (INFECTION..., 1996). O hipoclorito de sódio a $1 \%$ por 30 minutos é ativo contra os dois tipos de vírus; entretanto é inevitável a corrosão de instrumentais, como as moldeiras (FANTINATO et al., 1992).

O glutaraldeído a $2 \%$ por 30 minutos é um bom desinfetante; contudo é potencialmente carcinogênico se entrar em contato com a pele, a mucosa, ou quando inalado; por isso, seu manuseio exige cuidado especial (GARCIA et al., 1995).

Johnson e colaboradores (1998) afirmam, entretanto, que as substâncias mais usadas na odontologia para esse fim são o glutaraldeído $2 \%$ e o hipoclorito de sódio $1 \%$. Comenta que são substâncias de fácil acesso e que apresentam bons resultados no combate aos micro-organismos.

O digluconato de clorexidina a $0,5 \%$ pode ser usado como agente desinfetante de moldes, embora não aja sobre o vírus da hepatite $B$ (HBV) (BLAIR; WASSELL, 1996).

Segundo a British Dental Association, British Dental Trade Association e a Dental Laboratories Association, os iodóforos e os fenóis podem ser usados na desinfecção, embora o primeiro altere a composição dos materiais de moldagem, e último reaja com pasta de óxido de zinco-eugenol, e hidrocolóides reversíveis e irreversíveis.

Os métodos mais usados na desinfecção de moldes e modelos são: imersão, aspersão e a incorporação de desinfetante no hidrocolóide irreversível e no gesso (BRASIL, 2000).
No Quadro 1 são apresentadas propostas de técnicas de desinfecção de materiais de moldagem.

\begin{tabular}{|lllc}
\hline $\begin{array}{l}\text { MATERIAIS DE } \\
\text { MOLDAGEM }\end{array}$ & $\begin{array}{l}\text { SUBSTÂNCIAS } \\
\text { DESINFETANTES }\end{array}$ & $\begin{array}{l}\text { TÉCNICA DE } \\
\text { APLICAÇÃO }\end{array}$ & $\begin{array}{c}\text { TEMPO MÍNIMO } \\
\text { DE CONTATO }\end{array}$ \\
\hline Siliconas & Glutaraldeído a 2\% & Imersão & 10 minutos \\
Mercaptamas & Glutaraldeído a 2\% & Imersão & 10 minutos \\
Polissulfetos & Glutaraldeído a 2\% & Imersão & 10 minutos \\
Alginatos & lodóforos ou & Aspersão ou & 10 minutos \\
& Hipoclorito a 1\% & imersão & \\
& Glutaraldeído a 2\% & & 10 minutos \\
Poliésteres & Hipoclorito a 1\% & Imersão \\
Hidrocoloides & Hipoclorito a 1\% & Aspersão ou & 10 minutos \\
reversiveis & Glutaraldeído a 2\% & imersão & \\
Pasta zincoenólica & Hipoclorito de sódio a 1\% & Imersão & 10 minutos \\
& ou glutaldeído a 2\% & \\
\hline
\end{tabular}

Juntamente com os materiais de moldagem utilizados na prática clínica de odontologia, outros materiais de uso comum no tratamento por prótese entram em contato com fluídos bucais e devem ser, portanto, também desinfetados. No Quadro 2, são citadas técnicas e substâncias que poderão ser utilizadas para essa finalidade.

\begin{tabular}{|c|c|c|}
\hline $\begin{array}{l}\text { MATERIAIS } \\
\text { OUTROS }\end{array}$ & $\begin{array}{l}\text { SUBSTÂNCIA } \\
\text { UTILIZADA }\end{array}$ & $\begin{array}{l}\text { TÉCNICA E } \\
\text { DURAÇĀO }\end{array}$ \\
\hline Gesso & $\begin{array}{l}\text { Hipoclorito de sódio } \\
\text { a } 1 \%\end{array}$ & $\begin{array}{l}\text { Aspersão por } 10 \\
\text { minutos }\end{array}$ \\
\hline Registro de cera & Iodóforos & $\begin{array}{l}\text { Aspersāo por } 10 \\
\text { minutos }\end{array}$ \\
\hline Acrílicos & $\begin{array}{l}\text { Hipoclorito de sódio } \\
\text { a } 1 \% \text { ou glutaldeído a } \\
2 \%\end{array}$ & $\begin{array}{l}\text { Aspersão ou } \\
\text { imersão por } 10 \\
\text { minutos }\end{array}$ \\
\hline
\end{tabular}

\section{TÉCNICAS DE DESINFECÇÃO}

\section{Técnica da imersão}

Após a sua confecção, os moldes devem ser imediatamente lavados em água corrente e, logo 
em seguida, mantidos imersos na solução desinfetante (DISINFECTION..., 1991) por 10 minutos, num recipiente plástico com tampa; após esse tempo, lavar em água corrente (NASCIMENTO et al., 1999) (FIGURA 1).

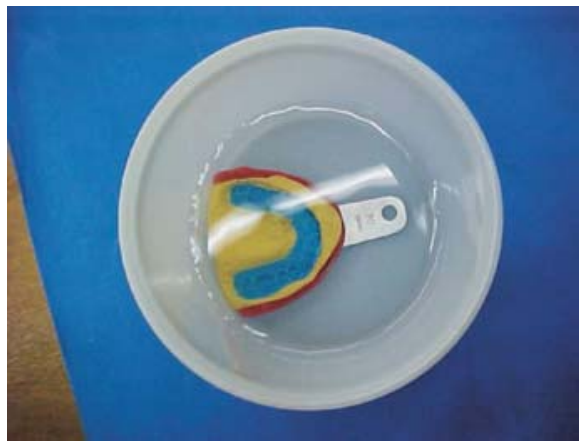

Figura 1 - Molde em silicona de condensação sendo submetido à técnica de imersão em solução de glutaraldeído a $2 \%$ por 10 minutos.

\section{Técnica da aspersão}

O molde, uma vez obtido, deve ser lavado em água corrente. Posteriormente, utiliza-se um spray para borrifar a superfície do material, tentando alcançar a maior área possível. A seguir, o molde deve ser colocado num recipiente plástico hermeticamente fechado, por 10 minutos. Após esse intervalo de tempo, deve-se lavá-lo em água corrente (INFECTION..., 1996) (FIGURA 2; FIGURA 3).

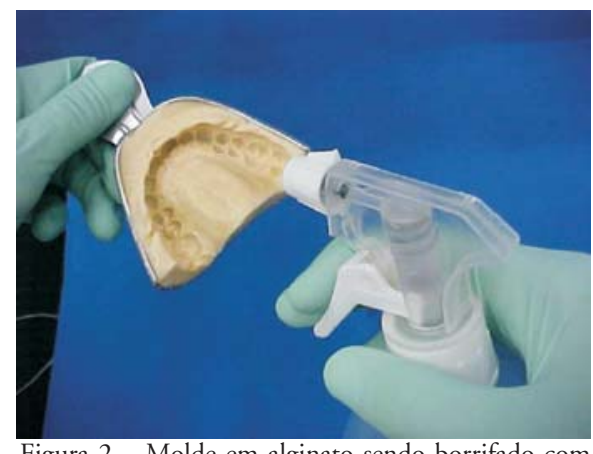
solução de hipoclorito de sódio a $1 \%$.

A lavagem inicial com água corrente tem por finalidade remover matéria orgânica que pode comprometer a ação de determinados de-

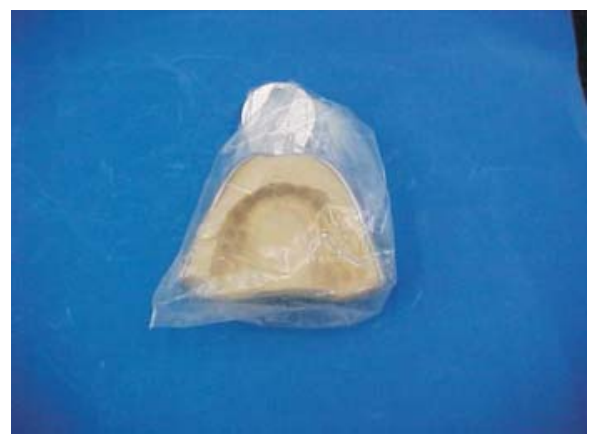

Figura 3 - Acondicionamento do molde em alginato, previamente borrifado com hipoclorito de sódio a $1 \%$, em invólucro plástico vedado, por 10 minutos

sinfetantes, diminuindo, assim, a carga de vírus e bactérias presentes no material de impressão. Essa lavagem é capaz de diminuir em cerca de 40 a $90 \%$ dos microorganismos presentes no molde (BLAIR; WASSELL, 1996; INFECTION..., 1996). Esse procedimento, no entanto, não dispensa o tratamento desinfetante, uma vez que é ineficaz na eliminação de todos os microorganismos presentes no molde (OSÓRIO et al., 1998).

A grande maioria dos trabalhos publicados mostra que o glutaraldeído $2 \%$, quando usado nas técnicas de imersão ou "spray" por $10 \mathrm{mi}$ nutos, não compromete clinicamente a qualidade dos modelos obtidos, seja quanto à estabilidade dimensional, seja quanto à reprodutibilidade de detalhes de superfície (NASCIMENTO et al., 1999).

A maioria dos autores concorda que a desinfecção de moldes deve ser feita por um tempo de 10 a 30 minutos ( INFECTION..., 1996; FONSECA et al., 1998; BRASIL, 2000).

Lepe e Johnson (1997), assim como Rios e colaboradores (1996), afirmam que, mesmo no tempo de 10 minutos, podem ocorrer alterações dimensionais, embora elas sejam clinicamente aceitáveis.

A desvantagem da imersão está relacionada à alteração dimensional; já a da aspersão é a observação de que os aerossóis, não atingindo todas as superfícies, podem não promover uma desinfecção adequada, além do fato de poderem ser tóxicos (GARCIA et al., 1995; BLAIR; WASSELL, 1996). 
Johnson e colaboradores (1998) acreditam que a capacidade de reprodução de detalhes, a estabilidade dimensional e o grau de umedecimento dos moldes não sejam criticamente afetados durante o processo de desinfecção.

Convém salientar que os modelos de gesso obtidos a partir de moldes que não sofreram tratamento desinfetante podem se tornar contaminados, e assim, passíveis de transmitir microorganismos a quem os manipula. A desinfecção do modelo de gesso deverá ser realizada na impossibilidade de desinfecção do molde (OSÓRIO et al., 1998).

\section{CONCLUSÃO}

A desinfecção de moldes e também dos modelos é de suma importância para a manutenção da cadeia asséptica no consultório odontológico. Diante da impossibilidade de utilização de métodos esterilizantes e substâncias desinfetantes por períodos prolongados, os métodos preconizados pela literatura são eficientes na prevenção da contaminação cruzada entre pacientes e a equipe odontológica.

\title{
Disinfection of impressions
}

\begin{abstract}
With the need of preventing the cross contamination between professionals, laboratory technicians and patients, a lot of techniques and substances have been used to promote biosecurity in dentistry. The impressions can be considered ways of transmitting infectious diseases, so it is required a special attention in the manipulation of these materials. There is some controversy in the process of disinfection of impressions. There are no universal guidelines on how to disinfect impressions. A variety of disinfection techniques, substances, and substance concentrations have been described. Furthermore disinfection procedures might cause dimensional changes in the impressions. An impression distorted by disinfection procedures will not accurately reproduce all the details of dental and oral anatomy present in a patient's oral cavity. The aim of this article is to present techniques of impression disinfection and also to increase awareness among dental professionals of the need of infection control in handling dental impressions.
\end{abstract}

Keywords: disinfection; impression; casts

\section{REFERÊNCIAS}

AUTIO, K.L. et al. Studies on cross contamination in the dental clinic. J. Am. Dent. Assoc, Chicago, v.100, p.358-361, Mar. 1980.

BASTOS, E.S.; SOUSA, V. O uso do alginato por alunos de graduação: Parte 1. PCL, Curitiba, v.5, n.23, p.31-37, mar./abr. 2003.

BLAIR, F.M.; WASSELL, R.W. A survey of the methods of disinfection of dental impressions used in dental hospitals in the United Kingdom.
Br. Dent. J., London, v.180, p.369-375, 1996.

BRASIL.Ministério da Saúde. Programa Nacional de DST/ AIDS. Controle de infecções e a prática odontológica em tempos de AIDS: manual de condutas. São Paulo: Comp. Litográf. Ipiranga, 2000.

DISINFECTION of impressions. ADA Council on Dental Materials, Instruments and Equipment. J. Am. Dent. Assoc., Chicago, 
v. 122, p.110, 1991.

FANTINATO, V. et al. Esterilização e desinfecção em odontologia: AIDS e Hepatite B. R. Bras. Odontol., Rio de Janeiro, v.49, n.5, p.3137, 1992.

FONSECA, R.G. et al. Estudo da influência de desinfetantes na estabilidade dimensional de materiais de moldagem: uma revisão de literatura. R. Faculdade Odontol. Lins, Lins, v.11, n.1, p.14-21, jan./jun. 1998.

GARCIA, A.R et al. Alteraçôes dimensionais produzidas em modelo de gesso decorrentes da imersão do molde de alginato em solução desinfetante. R. Odontol. UNESP, Marília, v.24, n.2, p.271-280, abr. 1995.

INFECTION control recommendation for the dental office and the dental laboratory. ADA Council on Scientific Affairs and ADA Council con Dental Practice. J. Am. Dent. Assoc., Chicago, v.127, p.672-680, 1996.

JOHNSON, G.H. et al. Dimensional stability and detail reproduction of irreversible hydrocolloid and elastomeric reimpressions disinfected by immersion. J. Prosthet. Dent., St. Louis, v.79, n.4, p.446-453, 1998.

KUGEL, G. et al. Disinfection and communication practices: a survey of U.S. dental laboratories. J. Am. Dent. Assoc., Chicago, v.131; p.786-792, June 2000.

LEPE, X.; JOHNSON, G.H. Accuracy of polyether and addition silicone after long-term immersion disinfection. J. Prosthet. Dent., St. Louis, v.78, n.3, p.245-249, Sept. 1997.

MATHIAS, S.; MATHIAS, A.; GUANDALINE, S. Recomendações para o controle de infecção em laboratório de prótese odontológica. PCL, Curitiba, v.1, n.1, p.21-
27, 1999 .

NASCIMENTO, W. et al. Desinfecção de moldes: como, quando e porquê. R. APCD, São Paulo, v.53, n.1, p.21-24, 1999.

OSÓRIO, A. et al. Avaliação da eficácia de agentes químicos na desinfecção de moldes de alginato. R. . Fac. Odontol. P. Alegre, Porto Alegre, v.39, n.1, p.17-19, jul.1998.

PALENIK, C.J.; BURKE, F.J.T.; MILLER, C.H. Strategies for dental clinic infection control. Dent. Update, Guildford, v.27, p.7-15, Jan./ Feb. 2000.

PAVARINA, A.C. et al. Influência da desinfecção de moldes na alteração dimensional de modelos de gesso. R. Odontol. UNESP, Marília, v.27, n.2, p.381-391, 1998.

PETERSON, L. et al. Cirurgia oral e maxilo facial contemporânea. 3.ed. Rio de Janeiro: Guanabara Koogan, 2000.

REUGGEBERG, F.A. et al. Sodium hypochlorite disinfection of irreversible hydrocolloid impression material. J. Prosthet. Dent., St. Louis, v.67, n.5, p.628-631, 1992.

RIOS, M.P. et al. Effects of chemical desinfectant solutions on the stability and accurancy of the dental impression complex. J. Prosthet. Dent, St. Louis, v.76, n.4, p.356-362, Oct. 1996.

ROWE, A.H.R.; FORREST, J.O. Dental impressions: the probability of contamination and method of desinfection. Br. Dent. J., London, v.145, n.9, p.184-186, Sept. 1978.

WANNMACHER, L.; FERREIRA, M. Farmacologia clínica para dentistas. 2.ed. Rio de Janeiro: Guanabara Koogan, 1995.

Recebido em / Received: 24/02/2004 Aceito em / Accepted: 28/09/2004 